$$
\text { Pontifícia } \underbrace{}_{\text {niversidade }} \text { Católica }_{\text {Do Rio de Janeiro }}
$$

Paulo Motta Maia de Oliveira Valério

Does Numerical Portability induce Competition?

\author{
DISSERTAÇÃO DE MESTRADO
}

DEPARTAMENTO DE ECONOMIA

Programa de Pós-Graduação em

Economia

Rio de Janeiro, April 2012 


$$
\text { Pontifícia } \underbrace{}_{\text {niversidade }} \text { Católica }_{\text {Do Rio de Janeiro }}
$$

Paulo Motta Maia de Oliveira Valério

Does Numerical Portability induce Competition?

\section{Dissertação de Mestrado}

Thesis presented to the Postgraduate Program in Economics of the Departamento de Economia,PUCRio as partial fulfillment for the degree of Mestre em Economia.

Advisors: João Manoel Pinho de Mello Juliano Junqueira Assunção

Rio de Janeiro, April 2012 
Paulo Motta Maia de Oliveira Valério

\title{
Does Numerical Portability induce Competition?
}

Thesis presented to the Postgraduate Program in Economics of the Departamento de Economia, PUC-Rio as partial fulfilment of the requirements for the degree of Mestre em Economia. Approved by the following commission.

\author{
João Manoel Pinho de Mello \\ Advisor \\ PUC-Rio
}

Juliano Junqueira Assunção

Co-advisor

PUC-Rio

Luis Henrique Bertolino Braido

FGV/EPGE

Vinicius Carrasco
PUC-Rio

Monica Herz

Coordinator of the Centro de Ciências Sociais - PUC-Rio

Rio de Janeiro, April 5th 2012 
All rights reserved

\section{Paulo Motta Maia de Oliveira Valério}

Undergraduate degree in Economics from PUC-Rio in 2008, and Master's degree in Economics from PUC-Rio in 2012.

Bibliographic data

Valério, Paulo Motta Maia de Oliveira

Does Numerical Portability induce Competition? / Paulo Motta Maia de Oliveira Valério; advisor: João Manoel Pinho de Mello $-2011$.

$41 \mathrm{f}$ : : il. ; $30 \mathrm{~cm}$

Dissertação (Mestrado em Economia)-Pontifícia Universidade Católica do Rio de Janeiro, Rio de Janeiro, 2012.

Inclui bibliografia

1. Economia - Teses. 2. Portabilidade numérica

3. Custo de Troca 4. Competição 5. Análise Empírica I. Mello, João Manoel Pinho de II. Assunção, Juliano Junqueira III. Pontifícia Universidade Católica do Rio de Janeiro. Departamento de Economia. IV. Título. 


\section{Agradecimentos}

Em primeiro lugar gostaria de agradecer a Deus pela sua misericórdia e por ter me guiado até a conclusão, com êxito, deste mestrado. Apesar de todas as dificuldades. Além disso, agradeço por ter me disciplinado com palavras de temor e me consolado com palavras de amor. Agradeço por sua presença constante e por sua restauração em minha vida. Sem esta força que me conduz nada disso seria possível.

Também gostaria de agradecer àquele a quem eu chamo de pai, Norval Valerio, que me susteve quando precisei, me amparou de todas as maneiras, além de todo seu amor e disciplina nos momentos cruciais da minha vida.

Gostaria de agradecer àquela a quem eu chamo de mãe. Por ter me amado, me educado e me conduzindo para o caminho da disciplina. Do qual eu tento não me desamparar.

Gostaria de mencionar também a importância de meu primo Pedro que sabiamente me aconselhou e foi fundamental tanto indiretamente quanto diretamente na conclusão da tese. Juntamente com ele foi de suma importância o apoio de meu amigo Matias que esteve sempre presente nos momentos mais difíceis.

É relevante ressaltar neste agradecimento toda a minha família e aqueles que eu amo. Sempre estiveram ao meu lado me dando seu braço direito como ajuda.

Ainda vale mencionar a importância de todos os amigos que fiz ao longo desses anos de mestrado e que influenciaram positivamente nesta árdua tarefa de obtenção de conhecimento.

Por fim, agradeço ao João Manoel Pinho de Melo, meu orientador, e ao Juliano Assunção, meu coorientador. Sem eles nada disso seria possível. Gostaria de agradecer também aos membros que participaram da banca: Vinicius Carrasco e Luís Braido. Por toda compreensão. 


\section{Resumo}

Paulo Motta Maia de Oliveira Valério. Portabilidade numérica induz competição? Rio de Janeiro, 2012. 41p. Dissertação de Mestrado Departamento de Economia, Pontifícia Universidade Católica do Rio de Janeiro.

Custos de troca existentes em certas indústrias são capazes de fornecer poder de mercado para as firmas que os detêm. O que se espera é que estes custos diminuam a concorrência entre as firmas uma vez que consumidores estarão mais inelásticos a variações de preço. No entanto, o que se nota neste trabalho é que dependendo da maturidade do mercado, firmas podem estar concorrendo por market share mais agressivamente para posteriormente aproveitar o custo de troca e o respectivo poder de mercado gerado por este custo. $\mathrm{O}$ que se observa no modelo é que se o custo de troca for diminuído em um momento de concorrência para obtenção de market share, preços podem aumentar. Este estudo analisa empiricamente a ocorrência da lei da portabilidade numérica no mercado de telefonia focando os efeitos na concorrência.

\section{Palavras-chave}

Portabilidade numérica; Custo de Troca; Competição; Análise Empírica 


\section{Abstract}

Paulo Motta Maia de Oliveira Valério. Does Numerical Portability induce

Competition? Rio de Janeiro, 2012. 41p. Dissertação de Mestrado -

Departamento de Economia, Pontifícia Universidade Católica do Rio de Janeiro.

Existing switching costs in certain industries are capable of providing market power to the holding firms. It's expected that these switching costs reduce the competition between the firms, as the consumers would likely to be more inelastic to the price variations. However, what's noticed in this paper is that depending of the market maturity; firms could be greedily competing for the market share to posteriorly take advantage of the switching cost. What's noticed is that if the switching cost is reduced in a competition moment of obtaining the marked share, prices would raise. This paper focuses the empirical study of the occurrence of the number portability in the phone market.

\section{Keywords}

Portability number; Switching cost; Competition; Empirical Analysis 


\section{Sumário}

1 Introduction 10

2 Theoretical Literature 12

3 Data and descriptive statistics 16

4 Klemperer model adapted 20

$\begin{array}{ll}\text { 4.1. Second period } & 21\end{array}$

4.2. second period 25

5 Main Results $\quad 29$

6 Robustness Test $\quad 37$

$\begin{array}{ll}7 \text { Conclusion } & 39\end{array}$

8 References $\quad 41$ 


\section{List of tables}

$\begin{array}{ll}\text { Table } 1 & 17\end{array}$

$\begin{array}{lr}\text { Table } 2 & 17\end{array}$

$\begin{array}{lr}\text { Table } 3 & 18\end{array}$

$\begin{array}{lr}\text { Table } 4 & 19\end{array}$

$\begin{array}{ll}\text { Table } 5 & 31\end{array}$

$\begin{array}{ll}\text { Table } 6 & 32\end{array}$

$\begin{array}{ll}\text { Table } 7 & 34\end{array}$

$\begin{array}{ll}\text { Table } 8 & 36\end{array}$

$\begin{array}{ll}\text { Table } 9 & 38\end{array}$ 